\title{
PESQUISA DE OPINIÃO: CONHECIMENTO DA REDE DE OUVIDORIA PELA COMUNIDADE ACADÊMICA DA UNIVERSIDADE DE PERNAMBUCO - UPE
}

\author{
Maria do Rosário Lapenda ${ }^{1}$ \\ Karla Júlia Marcelino²
}

\begin{abstract}
Resumo
Este artigo tem como objetivo aferir o conhecimento da comunidade universitária sobre a funcionalidade da Rede de Ouvidorias da Universidade de Pernambuco - UPE, através dos resultados de Pesquisa de Opinião. Optou-se pela Pesquisa de Campo, utilizando-se a distribuição de 250 (duzentos e cinquenta) questionários, nos diversos campi, dos quais 119 (cento e dezenove) foram tabulados. No quadro 1, os resultados foram uniformes nas diversas unidades onde a pesquisa foi aplicada. Observa-se que: 119 (cento e dezenove) pessoas dos segmentos docentes, discentes e técnicos administrativos responderam à pesquisa, das quais 37 (trinta e sete) são docentes, 35 (trinta e cinco) discentes e 47 (quarenta e sete) técnicos administrativos. Em análise isolada, representa um percentual de $31,09 \%$ de docentes e $39,50 \%$ de servidores técnicos administrativos. Já os discentes perfazem um percentual de 29,41\%. Evidencia-se a necessidade de maior divulgação da Rede de Ouvidorias da Universidade de Pernambuco - UPE, contudo, variáveis como contenção de despesas e recursos escassos no plano governamental dificultam, sobremaneira, o processo complexo de divulgação em uma instituição multicampi, com turnover de pessoas.
\end{abstract}

Palavras-chave: Conhecimento. Ouvidoria universitária. Rede de Ouvidorias. Comunidade.

\section{DOI:10.37814/2594-5068.2020v3.p45-55}

1 Ouvidora Central da Universidade de Pernambuco - UPE. Graduada em Psicologia. Especialista em Psicologia do Trabalho pelo Conselho Regional de Psicologia/02. Especialista em Saúde Pública pela Universidade de Pernambuco - UPE. Especialista em Dinâmica de Grupo. Instrutora de Treinamentos na Área Comportamental. Ex-presidente da Associação Brasileira de Ouvidores/Seccional Pernambuco, no período de 2014 a 2018. (mrlapenda2@hotmail.com)

2 Graduação em Serviço Social. Foi instrutora do Curso Implantação e Gestão de Ouvidoria no Cefospe e Gestão de Ouvidoria da Pós-Graduação na ESURP. Especialista em Gestão Governamental (Fundação Getulio Vargas), Gestão Pública e Serviços Sociais (UFPE), Intervenção Psicossocial à Família no Judiciário (UFPE) e Psicologia Organizacional - Nupesf. Ministra palestras no Estado e na área privada. Elaborou a Cartilha de Assédio Moral do Estado de PE. Implantou a Ouvidoria-Geral do Estado e a Rede de Ouvidorias. É membro da Comissão da Revista Científica da ABO Nacional (karlajuliam@bol.com.br) 


\begin{abstract}
This article aims to assess the knowledge of the University Community about the functionality of the Network of Ombudsmen of the University of Pernambuco - UPE, through the results of the Opinion Survey. The Field Survey was used, using the distribution of 250 (two hundred and fifty) questionnaires, in the various campuses, among which 119 (one hundred and nineteen) were tabulated. In table 1, the results were uniform in the different units where the research was applied. It is observed that: 119 (one hundred and nineteen) people from the teaching, students and administrative technicians segments answered the research, of which 37 (thirty seven) are teachers, 35 (thirty five) students and 47 (forty seven) administrative technicians. In an isolated analysis, it represents a percentage of $31.09 \%$ of teachers and $39.50 \%$ of technical administrative staff. Already the students make up a percentage of $29.41 \%$. There is evidence of the need for greater dissemination of the University of Pernambuco - UPE's Ombudsman Network, however, variables such as containment of scarce resources and expenditures at the governmental level make it difficult to communicate the complex process of disclosure in a multicamp institution, with turnover of people.
\end{abstract}

Keywords: Knowledge. University Ombudsman. Ombudsman Network. Academic community. 


\section{INTRODUÇÃO}

A Universidade de Pernambuco - UPE tem como missão promover a educação mediante atividades de ensino, pesquisa e extensão que propiciem, de modo reflexivo e crítico, a interação com a sociedade local, regional, nacional e internacional, com formação integral, humanística, científica, tecnológica, ética, política e socioambiental, de profissionais capazes de contribuir para o desenvolvimento sociocultural, tecnológico e econômico do Estado de Pernambuco e do Nordeste. Sua visão é ser reconhecida pela sociedade e por diversas instâncias de governo, graças à sua contribuição para o desenvolvimento sustentável em todas as regiões do Estado, em razão da excelência no ensino, na pesquisa e extensão universitária, assumindo-se, definitivamente, como Universidade estatal, pública e gratuita.

A Universidade de Pernambuco - UPE está presente em todas as regiões do Estado e o seu complexo multicampi é formado por quinze unidades de ensino, três grandes hospitais e a Reitoria, assim distribuídos nos campi:

- Campi Metropolitanos do Recife, que incluem o Campus de Santo Amaro com quatro Unidades de Ensino da Saúde, o Campus Benfica com duas Unidades de Ensino e o Campus de Camaragibe com uma Unidade de Ensino;

- Campi Mata Norte, Caruaru, multicampi Garanhuns (Salgueiro, Petrolina, Arcoverde, Serra Talhada) e Mata Sul.

As Unidades Hospitalares de Ensino e Complexo Hospitalar são: Hospital Universitário Oswaldo Cruz/Huoc; Pronto-Socorro Cardiológico Universitário Professor Luiz Tavares/Procape; e Centro Integrado de Saúde Amaury de Medeiros/Cisam, que formam o complexo hospitalar da UPE.

No sistema multicampi da UPE, a Reitoria, como órgão executivo superior que se situa no Campus Metropolitano de Recife, possui órgãos suplementares de apoio e três Escolas de Aplicação de Ensino Fundamental e Médio - Petrolina, Garanhuns e Nazaré da Mata, para lócus de prática e da experiência das Licenciaturas, além de uma Escola de Ensino Fundamental e Médio e uma Escola de Ensino Infantil e Fundamental da rede municipal de ensino da cidade de Recife.

A Ouvidoria Central da Universidade de Pernambuco - UPE foi implantada no dia 15 de dezembro de 2008, através da Portaria n ${ }^{\circ}$ 1017/2008 do Magnífico Reitor, com publicação no dia 8.1.2009 no Diário Oficial do Estado. Ela coordena as Ouvidorias Setoriais (situadas nas Unidades de Saúde) do Centro Integrado de Saúde Amaury de Medeiros - Cisam, do Hospital Universitário Oswaldo Cruz/Huoc e do Pronto-Socorro Cardiológico de Pernambuco - Procape.

A Rede de Ouvidorias da Universidade de Pernambuco - UPE funciona como canal de comunicação na coparticipação do cidadão para elevar, continuamente, os padrões de transparência, presteza e segurança nas atividades desenvolvidas pela Instituição e o fortalecimento da interlocução com o cidadão-usuário e a sociedade, inclusive com atendimentos de demandas em nível nacional e internacional. A maioria das quinze demandas internacionais, oriundas de países como Itália, Colômbia, Chile e Portugal recebidas pela Ouvidoria da UPE até 2019, versou sobre a revalidação do diploma médico e mobilidade acadêmica.

Avaliar o impacto das demandas oriundas da população nos órgãos públicos, através da proposição de ações de melhoria para os gestores, constitui atualmente uma das maiores atribuições 
das Ouvidorias Públicas. Nesse sentido, o Ouvidor tem um desafio a superar no seu cotidiano profissional: interpretar fidedignamente os anseios dos cidadãos, mediar e conciliar os conflitos e cobrar, das áreas responsáveis, as possíveis soluções para o atendimento dessas demandas.

Este artigo tem como objetivo aferir o conhecimento da comunidade universitária sobre a funcionalidade da Rede de Ouvidorias da Universidade de Pernambuco - UPE, através dos resultados da Pesquisa de Opinião realizada no primeiro trimestre do ano de 2019.

\section{MÉTODO}

Para a aplicação da pesquisa, inicialmente foi realizada uma reunião com as Gerências Setoriais de Recursos Humanos das Unidades de Educação e Educação e Saúde da Universidade de Pernambuco - UPE e o representante da Coordenação Central de Recursos Humanos da Reitoria, em janeiro de 2019, os quais ficaram responsáveis pela divulgação, coleta de dados e devolução dos questionários respondidos à Ouvidoria Central (a pesquisa encerrou-se no mês de maio).

De acordo com os dados emitidos pela Pró-Reitoria de Planejamento/Proplan, no site www. upe.br, em números de 2019, com base no exercício de 2018, a Universidade de Pernambuco - UPE apresentava um total de 24.123 (vinte e quatro mil, cento e vinte e três) pessoas que compõem o seu quadro Institucional. Foram distribuídos 250 (duzentos e cinquenta) questionários em seus diversos campi e Reitoria. Do total de pessoas que responderam à pesquisa: 37 (trinta e sete) são docentes, equivalendo a 31,09\%; 35 (trinta e cinco) discentes; 47 (quarenta e sete) técnicos administrativos, representando $39,50 \%$. Os discentes perfazem um percentual de $29,41 \%$ do universo de 14.224 (catorze mil, duzentos e vinte e quatro).

Estatisticamente, analisou-se, por meio da variável regra de três simples, o quantitativo dos 119 (cento e dezenove) questionários respondidos, entre os 250 distribuídos, de acordo com: Quadro 1 (Vínculo Institucional/Campus); Quadro 2/Gráfico2 (Gênero); Quadro 3/Gráfico 3 (Total de questionários respondidos por idade); e Quadro 4/Gráfico 4 (Enquetes). O questionário constou de enquetes realizadas através de 9 (nove) perguntas fechadas (anexo 1).

A análise foi delineada com base nos dados colhidos, no período de janeiro a maio de 2019 , por meio de uma pesquisa de campo realizada nas Unidades de Educação e Educação e Saúde desta Universidade e Reitoria com apoio do setor de Recursos Humanos.

Foi utilizado o método da regra de três simples para realização e tratamento estatístico das 9 (nove) perguntas fechadas do questionário, assim distribuídas e analisadas pelo número absoluto das respostas.

\section{ANÁLISE DOS RESULTADOS}

As demandas da Ouvidoria Central da Universidade de Pernambuco - UPE são recebidas através do Sistema Gestão do Conhecimento - Gcon, o qual interliga toda a Rede de Ouvidorias 
que é coordenada pela Ouvidoria-Geral do Estado/Secretaria da Controladoria-Geral do Estado de Pernambuco/SCGE/PE.

O Sistema de Informações de Ouvidorias tem quatro funções principais, conforme a autora MARCELINO (2010):

Criar base de dados para levantamentos estatísticos; dar tratamento às manifestações dos usuários, controlando prazos; promover o conhecimento sobre o público-alvo e o relacionamento com este, medindo satisfação com a solução apresentada e possibilitar a melhoria dos processos organizacionais.

No ano de 2018, a Ouvidoria Central Universitária da Universidade de Pernambuco registrou 584 (quinhentos e oitenta e quatro) manifestações tipificadas como: denúncias, reclamações, solicitações, elogios e Pedidos de Acesso à Informação - PAI, com uma resolutividade de 96,4\%. Quanto à Rede de Ouvidorias que engloba os três Hospitais Universitários, atingiu-se um quantitativo de 1.994 (um mil, novecentos e noventa e quatro) demandas recebidas na Universidade de Pernambuco.

No total de 119 (cento e dezenove) questionários respondidos de acordo com o Quadro 1, os resultados foram uniformes nas diversas unidades onde a pesquisa foi aplicada.

\section{QUADRO 1 - Vínculo Institucional}

\begin{tabular}{|l|l|l|l|l|l|l|l|l|}
\hline \multirow{2}{*}{ Vínculo } & \multirow{2}{*}{ Reitoria } & \multicolumn{9}{|c|}{ C A M U S } & \multirow{2}{*}{ Total } \\
\cline { 3 - 10 } & & Camaragibe & $\begin{array}{l}\text { Campi } \\
\text { Garanhuns }\end{array}$ & $\begin{array}{l}\text { Mata } \\
\text { Norte }\end{array}$ & Benfica & $\begin{array}{l}\text { Santo } \\
\text { Amaro }\end{array}$ & \\
\hline Docente & 10 & 1 & 7 & 5 & 3 & 11 & 37 & 31,09 \\
\hline Discente & 2 & 9 & 5 & 5 & & 14 & 35 & 29,41 \\
\hline Técnicos & 12 & & 2 & 2 & 1 & 30 & 47 & 39,50 \\
\hline Total & 24 & 10 & 14 & 12 & 4 & 55 & 119 & 100 \\
\hline
\end{tabular}

Fonte: Questionários aplicados nos diversos campi UPE

Observa-se que, do total de 24.123 (vinte e quatro mil, cento e vinte e três) pessoas que compõem o seu quadro Institucional, 37 (trinta e sete) docentes responderam à pesquisa, perfazendo um percentual de 31,09\%. Dos 14.224 (catorze mil, duzentos e vinte e quatro) que são discentes, apenas 35 (trinta e cinco) responderam à pesquisa, perfazendo um percentual de $29,41 \%$. Não obtivemos amostragem de alunos das diversas categorias de Pós-Graduação e Educação a Distância. Entre os técnicos administrativos, 47(quarenta e sete) responderam à pesquisa, perfazendo um total de $39,50 \%$. 


\section{QUADRO 2 - Gênero}

\begin{tabular}{|c|c|c|c|c|c|c|c|c|}
\hline \multirow[b]{2}{*}{ Gênero } & \multirow[b]{2}{*}{ Reitoria } & \multicolumn{5}{|c|}{$C A M P U S$} & \multirow[b]{2}{*}{ Total } & \multirow[b]{2}{*}{$\%$} \\
\hline & & Camaragibe & $\begin{array}{l}\text { Campi } \\
\text { Garanhuns }\end{array}$ & Mata Norte & Benfica & $\begin{array}{l}\text { Santo } \\
\text { Amaro }\end{array}$ & & \\
\hline Masculino & 7 & 3 & 5 & 6 & 2 & 18 & 41 & 34,45 \\
\hline Feminino & 17 & 6 & 9 & 5 & 2 & 37 & 76 & 63,87 \\
\hline Outros & & 1 & & 1 & & & 2 & 1,68 \\
\hline Total & 24 & 10 & 14 & 12 & 4 & 55 & 119 & 100 \\
\hline
\end{tabular}

Fonte: Questionários aplicados nos diversos campi UPE

\section{GRÁFICO 2 - Gênero}

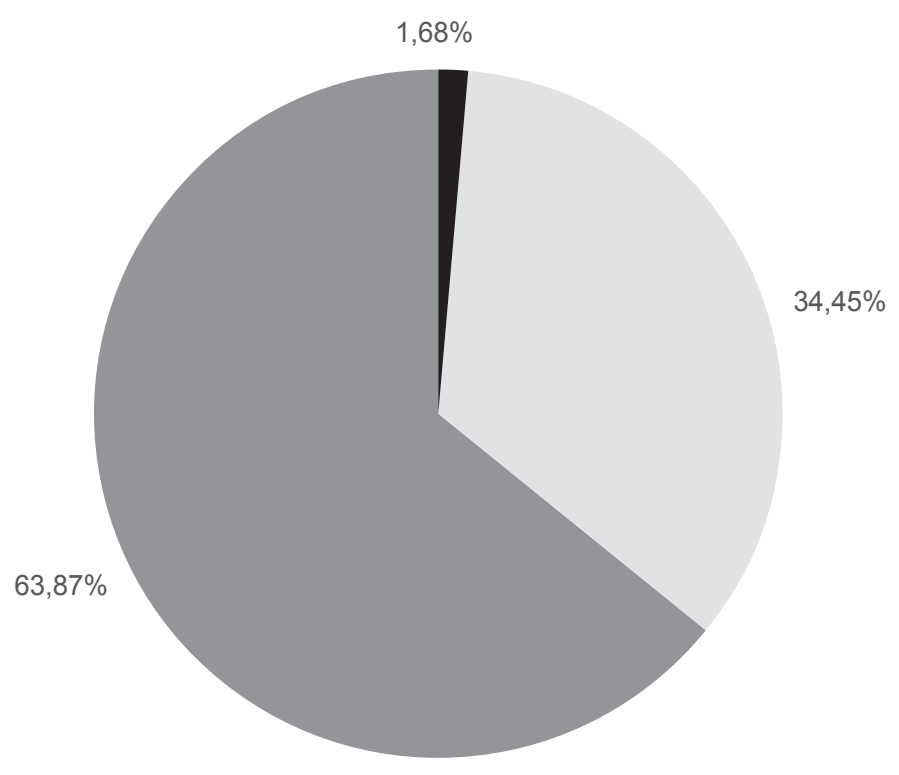

Fonte: Questionários aplicados nos diversos campi UPE

Observa-se no Quadro 2 e no Gráfico 2 o gênero dos entrevistados de acordo com o campus em que atuam. Dos 119 (cento e dezenove) questionários aplicados, 76 (setenta e seis) pessoas que responderam à enquete pertencem ao gênero feminino (63,87\%), 41 (quarenta e uma) ao gênero masculino $(34,45 \%)$ e 2 (duas) a outros gêneros $(1,68 \%)$. 


\section{QUADRO 3 - Faixa Etária}

\begin{tabular}{|c|c|c|c|c|c|c|c|c|}
\hline \multirow{2}{*}{$\begin{array}{l}\text { Faixa } \\
\text { Etária }\end{array}$} & \multirow[b]{2}{*}{ Reitoria } & \multicolumn{5}{|c|}{ CAMPUS } & \multirow[b]{2}{*}{ Total } & \multirow[b]{2}{*}{$\%$} \\
\hline & & Camaragibe & $\begin{array}{l}\text { Campi } \\
\text { Garanhuns }\end{array}$ & $\begin{array}{l}\text { Mata } \\
\text { Norte }\end{array}$ & Benfica & $\begin{array}{l}\text { Santo } \\
\text { Amaro }\end{array}$ & & \\
\hline $\begin{array}{l}19 \text { a } 30 \\
\text { anos }\end{array}$ & 3 & 9 & 5 & 5 & & 17 & 39 & 44,31 \\
\hline $\begin{array}{l}31 \text { a } 40 \\
\text { anos }\end{array}$ & 2 & & 4 & 3 & & 3 & 12 & 13,63 \\
\hline $\begin{array}{l}41 \text { a } 50 \\
\text { anos }\end{array}$ & 1 & 1 & 2 & & 1 & 6 & 11 & 12,50 \\
\hline $\begin{array}{l}51 \text { a } 60 \\
\text { anos }\end{array}$ & 4 & & 1 & & & 16 & 21 & 23,86 \\
\hline $\begin{array}{l}61 \text { a } 70 \\
\text { anos }\end{array}$ & & & & & 1 & 4 & 5 & 5,68 \\
\hline Total & 10 & 10 & 12 & 8 & 2 & 46 & 88 & 100 \\
\hline
\end{tabular}

Fonte: Questionários aplicados nos diversos campi UPE

\section{GRÁFICO 3 - Faixa Etária}

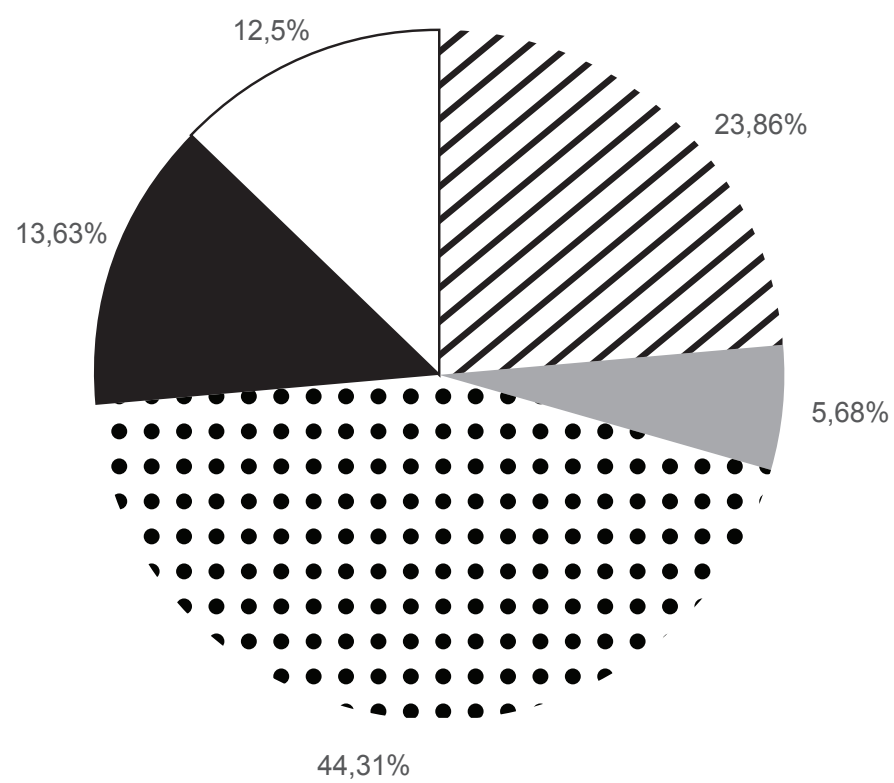

$44,31 \%$

Fonte: Questionários aplicados nos diversos campi UPE 
Apresenta-se no Quadro 3 e no Gráfico 3 a faixa etária dos entrevistados. Dos 119 (cento e dezenove) questionários, 88 (oitenta e oito) foram respondidos. Observa-se o predomínio da faixa etária dos 19 (dezenove) a 30 (trinta) anos, com representação de 39 questionários respondidos, perfazendo um total de 44,31\%. Na faixa etária de 31 (trinta e um) a 40 (quarenta), 12 (doze) pessoas responderam, perfazendo o percentual de 13,63\%; na de 41 (quarenta e um) a 50 (cinquenta), 11 (onze) pessoas responderam, equivalendo a 12,50\%; na de 51 (cinquenta e um) a 60 (sessenta), 21 (vinte e uma) pessoas responderam, perfazendo um percentual de 23,86\%; na de 61 (sessenta e um) a 70 (setenta), 5 (cinco) pessoas responderam, atingindo o percentual de $5,68 \%$.

\section{QUADRO 4 - Perguntas Formuladas}

\begin{tabular}{|c|c|c|c|c|c|c|c|c|c|c|c|c|c|c|c|c|c|}
\hline \multirow[t]{2}{*}{ Perguntas Formuladas } & \multicolumn{2}{|c|}{ Reitoria } & \multicolumn{2}{|c|}{$\begin{array}{l}\text { Campi } \\
\text { Garanhuns }\end{array}$} & \multicolumn{2}{|c|}{$\begin{array}{l}\text { Campus } \\
\text { Mata Norte }\end{array}$} & \multicolumn{2}{|c|}{$\begin{array}{l}\text { Campus } \\
\text { Santo } \\
\text { Amaro }\end{array}$} & \multicolumn{2}{|c|}{$\begin{array}{l}\text { Campus } \\
\text { Camaragibe }\end{array}$} & \multicolumn{2}{|c|}{$\begin{array}{l}\text { Campus } \\
\text { Benfica }\end{array}$} & \multicolumn{3}{|c|}{ TOTAL } & \multicolumn{2}{|l|}{$\%$} \\
\hline & Sim & Não & Sim & Não & Sim & Não & Sim & Não & Sim & Não & Sim & Não & Sim & Não & Geral & Sim & Não \\
\hline $\begin{array}{l}\text { 1.Você conhece a Rede de } \\
\text { Ouvidoria? }\end{array}$ & 23 & 1 & 3 & 11 & 3 & 9 & 34 & 21 & & 10 & 1 & 3 & 64 & 55 & 119 & 53,78 & 46,22 \\
\hline $\begin{array}{l}\text { 2. Você já acionou uma das } \\
\text { Ouvidorias? }\end{array}$ & 2 & 22 & 3 & 11 & 2 & 10 & 6 & 49 & & 10 & & 4 & 13 & 106 & 119 & 10,92 & 89,08 \\
\hline $\begin{array}{l}\text { 3. Você sabe qual o papel de } \\
\text { uma Ouvidoria? }\end{array}$ & 23 & 1 & 8 & 6 & 9 & 3 & 46 & 9 & 3 & 7 & 3 & 1 & 92 & 27 & 119 & 77,31 & 22,69 \\
\hline $\begin{array}{l}\text { 4. Você conhece o relatório } \\
\text { com dados estatísticos } \\
\text { postados? }\end{array}$ & 9 & 15 & 13 & 1 & 1 & 11 & 16 & 39 & & 10 & & 4 & 39 & 80 & 119 & 32,77 & 67,23 \\
\hline $\begin{array}{l}\text { 5. Você conhece as formas do } \\
\text { usuário acessar a Ouvidoria? }\end{array}$ & 21 & 3 & 4 & 10 & 3 & 9 & 31 & 24 & 1 & 9 & 3 & 1 & 63 & 56 & 119 & 52,94 & 47,06 \\
\hline 6. Se SIM, obteve retorno? & 2 & 22 & 1 & 13 & 2 & 10 & 3 & 52 & & 10 & & 4 & 8 & 111 & 119 & 6,72 & 93,28 \\
\hline $\begin{array}{l}\text { 7. Você sabe dizer o que é } \\
\text { transparência? }\end{array}$ & 7 & 17 & 1 & 13 & 8 & 4 & 15 & 40 & & 10 & & 4 & 31 & 88 & 119 & 22,69 & 77,31 \\
\hline $\begin{array}{l}\text { 8. Você conhece a página } \\
\text { de Acesso à Informação da } \\
\text { Universidade? }\end{array}$ & 11 & 13 & 2 & 12 & 3 & 9 & 12 & 43 & 9 & 1 & 2 & 2 & 39 & 80 & 119 & 32,77 & 67,23 \\
\hline $\begin{array}{l}\text { 9. Você já conhece a Carta de } \\
\text { Serviços Normatizada? }\end{array}$ & 18 & 6 & & 14 & 5 & 7 & 13 & 42 & & 10 & & 4 & 36 & 83 & 119 & 30,25 & 69,75 \\
\hline $\mathrm{TOTAL}$ & 116 & 100 & 35 & 91 & 36 & 72 & 176 & 319 & 13 & 77 & 9 & 27 & 385 & 686 & 1071 & 35,94 & 64,06 \\
\hline TOTAL GERAL & 216 & & 126 & & 108 & & 495 & & 90 & & 36 & & 1071 & & 1071 & 100 & \\
\hline
\end{tabular}

Fonte: Questionários aplicados nos diversos campi UPE 


\section{GRÁFICO 4 - Perguntas Formuladas}

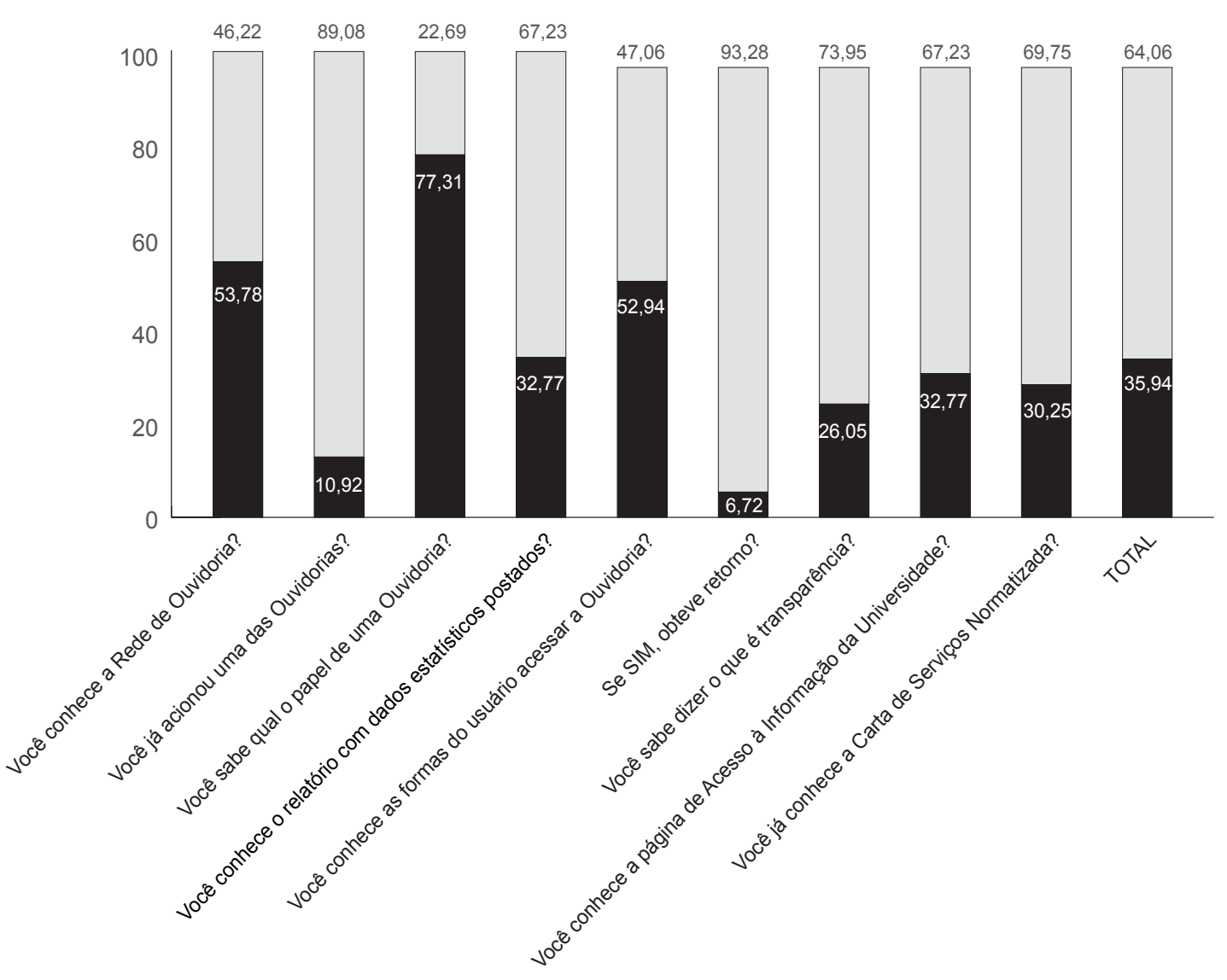

Fonte: Questionários Aplicados nos diversos Campi UPE

Demonstram-se no Quadro 4 e no Gráfico 4 os resultados das perguntas formuladas: Na primeira pergunta sobre o Conhecimento da Rede de Ouvidoria da UPE, observa-se que 53,78\% dos entrevistados conhecem a Rede de Ouvidoria da Universidade de Pernambuco - UPE e 46,22\% desconhecem. Na segunda pergunta, “Você já acionou uma das Ouvidorias da UPE?”, nota-se que apenas 10,92\% dos entrevistados acionaram a Rede de Ouvidorias da UPE e 89,08\% não acionaram. Na terceira pergunta, "Você sabe o papel de uma Ouvidoria na Instituição?", percebe-se que $77,31 \%$ conhecem a sua importância e $22,69 \%$ não conhecem. Na quarta pergunta evidencia-se que $32,77 \%$ conhecem o Relatório com dados estatísticos postados no site e $67,23 \%$ desconhecem. À quinta pergunta, "Quanto às formas do usuário acessar a Ouvidoria", 52,94\% responderam que as conhecem e 47,06\%, que as desconhecem. À sexta pergunta, "Se Sim, obteve retorno?", apenas $6,72 \%$ responderam que sim e $93,28 \%$ responderam que não, o que contradiz o percentual de resolutividade da Ouvidoria, que é superior a 96,4\%. Em relação à sétima pergunta, "Você sabe 
dizer o que é transparência passiva e ativa?", a pesquisa teve como intenção aferir o conhecimento das Transparências Ativa e Passiva dos entrevistados, em observância à Lei Federal 12.527 de novembro de 2011 e à Lei Estadual 14.408 de outubro de 2012, regulada pelo Decreto Estadual 38.787 de outubro de 2012 . No caso, apenas $22,69 \%$ conhecem e $77,31 \%$ desconhecem. À oitava pergunta, "Você conhece a página de Acesso à Informação da Universidade?", 32,77\% responderam que conhecem e 67,23\%, que desconhecem. A Ouvidoria Central da Universidade de Pernambuco tem a página na seção prestação de serviços, no site institucional www.upe.br, desde o ano de 2010. Quanto à nona pergunta, relativa ao conhecimento da Carta de Serviços, normatizada pela Lei Federal $n^{\circ} 13.460$ de junho de 2017, pela Lei Estadual $n^{\circ} 16.420$ de setembro de 2018 e pelo Decreto Estadual $n^{\circ} 45.883$ de abril de 2018, 30,25\% responderam que conhecem e 69,75\%, que desconhecem.

\section{CONSIDERAÇÕES FINAIS}

Este artigo tem como objetivo aferir o conhecimento da comunidade universitária sobre a funcionalidade da Rede de Ouvidorias da Universidade de Pernambuco - UPE, através dos resultados da Pesquisa de Opinião. Optou-se pela Pesquisa de Campo, utilizando-se a distribuição de 250 (duzentos e cinquenta) questionários, nos diversos campi, dos quais 119 foram tabulados.

Para a divulgação da Rede de Ouvidorias da UPE foram utilizadas ferramentas como o site Institucional, as Redes Sociais, e-mails, Ouvidorias Itinerantes, palestras ministradas pela Ouvidoria Central em diversos setores institucionais, como o Conselho Universitário - Consun.

A experiência vivenciada pela Rede de Ouvidoria da Universidade de Pernambuco demonstra que é possível trabalhar concretamente na perspectiva de que os cidadãos encontrarão nas Ouvidorias o canal legítimo de representação dos interesses e necessidades da sociedade. Com a consolidação da Rede de Ouvidores em Pernambuco, torna-se mais eficaz o processo de intercâmbio e comunicação entre os cidadãos usuários e o Estado, possibilitando uma maior transparência e prestação de contas dos seus resultados e devida avaliação quanto ao nível de satisfação desses usuários em relação à gestão pública.

Os resultados das 119 entrevistas da pesquisa refletem a necessidade de uma ampla divulgação do trabalho da Ouvidoria, já que 46,22\% dos respondentes desconhecem a Rede de Ouvidoria da UPE; apenas 10,92\% acionaram a Rede de Ouvidorias da UPE; 32,77\% conhecem o relatório com dados estatísticos postados no site; $47,06 \%$ desconhecem as formas de acessar a Ouvidoria; apenas 22,69\% sabem o que é Transparência Ativa e Passiva; assim como a Página de Acesso à Informação da Universidade é desconhecida por cerca de $67,23 \%$ dos entrevistados.

Evidencia-se a necessidade de maior divulgação da Rede de Ouvidorias da Universidade de Pernambuco - UPE na comunidade universitária, assim como a urgente disseminação da Lei de Acesso à Informação e os processos de Transparência Ativa e Passiva, onde variáveis como contenção de despesas e recursos escassos em nível governamental dificultam sobremaneira o processo complexo de comunicação em uma instituição multicampi, com turnover de pessoas entre sua comunidade acadêmica. Sugere-se que sejam feitos estudos posteriores que aprofundem o 
nível de conhecimento da comunidade universitária sobre a funcionalidade da Rede de Ouvidorias da Universidade de Pernambuco - UPE.

\section{REFERÊNCIAS}

BRASIL. Constituição (1988). Constituição da República Federativa do Brasil. Brasília, DF: Senado Federal: Centro Gráfico, 1988. 292 p.

Presidência da República. Lei n 12.527 de 18 de novembro de 2011: regula o acesso a informações previsto no inciso XXXIII do art. $5^{\circ}$, no inciso II do $\S 3^{\circ}$ do art. 37 e no $\S 2^{\circ}$ do art. 216 da Constituição Federal; altera a Lei $\mathrm{n}^{\circ}$ 8.112, de 11 de dezembro de 1990; revoga a Lei $\mathrm{n}^{\circ} 11.111$, de 5 de maio de 2005, e dispositivos da Lei no 8.159, de 8 de janeiro de 1991; e dá outras providências. Brasília, 2011. Disponível em: <http://www.planalto.gov. br/ccivil_03/_ato2011-2014/2011/lei/l12527.htm>. Acesso em: 25 mar. 2017.

Presidência da República. Lei n 13.460 de 26 de junho de 2017: dispõe sobre participação, proteção, defesa dos direitos do usuário dos serviços públicos da Administração Pública, e dá outras providências. Brasília, 2017.

MARCELINO, Karla Júlia. Importância da estatística na atualidade. Disponível em: <http://www. ouvidoria.pe.gov.br. Acesso: em 26 jun. 2019.

PERNAMBUCO. Secretaria da Controladoria-Geral do Estado de Pernambuco/SCGE/Manual de Procedimentos da Rede de Ouvidoria do Estado de Pernambuco (Página Eletrônica da Ouvidoria Central em www.upe.br e Página da Ouvidoria-Geral do Estado de Pernambuco/OGE em <http://www2.ouvidoria.pe.gov.br/c/document_library/get_file?p_I_id=7364186\&folderld=7370971\&name=DLFE-53435.pdf $>$ ).

Assembleia Legislativa do Estado. Lei n 14.804, de 29 de outubro de 2012: regula o acesso a informações, no âmbito do Poder Executivo Estadual, e dá outras providências. Disponível em: <http://legis.alepe.pe.gov.br/arquivoTexto.aspx ?tiponorma=1\&numero=14804\& complemento=0\&ano=2012\&tipo=>. Acesso em: 17 mar. 2016.

Secretaria da Controladoria do Estado de Pernambuco. Decreto n 38.787 de 30 de outubro de 2012: regulamenta a Lei $n^{\circ} 14.804$, de 29 de outubro de 2012, que dispõe sobre o acesso a informações, no âmbito do Poder Executivo Estadual, e dá outras providências. Recife, 2012. Disponível em: <http://www.secti. pe. gov. br/ wp-content/uploads/2016/03/DECRETO-N\%C2\%BA-38.787.-2012-atualizado-at\%C3\%A9-Decreto-N\%C2\%BA-42.055-17.08.2015.pdf>. Acesso em: 10 maio 2019.

Plano de Desenvolvimento Institucional da UPE 2020 a 2023; Site http://www.upe.br/anexos/PDI/PDI_ UPE_2019_A_2023.pdf. Acesso em: 10 maio 2019. 